\title{
ESTUDO DA SECAGEM DE PARTÍCULAS DE AMIDO- ALGINATO PRODUZIDAS POR GELIFICAÇÃO IÔNICA
}

\author{
G. B. LIMA, G. C. DACANAL* \\ Universidade de São Paulo, Faculdade de Zootecnia e Engenharia de Alimentos, \\ Departamento de Engenharia de Alimentos \\ *E-mail para contato: gdacanal@usp.br
}

\begin{abstract}
RESUMO - Neste trabalho estudou-se a cinética de secagem de partículas de amido de milho aglomeradas pelo método de gotejamento. As partículas produzidas foram submetidas à secagem em estufa convectiva a $60{ }^{\circ} \mathrm{C}$ com velocidade do ar a $0,2 \mathrm{~m} / \mathrm{s}$. Durante a secagem, as amostras foram pesadas em intervalos de $5 \mathrm{~min}$, em um tempo total de 120 minutos. As amostras permaneceram por mais $20 \mathrm{~h}$ de secagem, para a determinação da umidade de equilíbrio, que foi igual a $5,08 \%$. As partículas aglomeradas foram fotografadas, a fim de se mensurar os parâmetros de forma, o tamanho médio e o encolhimento das partículas durante a secagem. O diâmetro médio de partículas reduziu de 2254 $\mu \mathrm{m}$ para $1809 \mu \mathrm{m}$, em 120 min de secagem. O conteúdo de umidade, em base úmida, reduziu de $63,9 \%$ para 5,45 \%. O efeito de encolhimento não resultou na alteração da forma das partículas, uma vez que os valores de circularidade $(0,85)$, arredondamento $(0,91)$, elongação $(1,11)$ e compacidade $(0,94)$ foram mantidos constantes. O valor do Span, ou dispersão da distribuição de tamanho de partículas, manteve-se ao redor de $0,30 \pm 0,1$, o que indica que ao longo do tempo de secagem as partículas com maiores e menores tamanhos apresentaram a mesma taxa de encolhimento. O perfil de cinética de secagem de umidade adimensional, em base seca, apresentou bom ajuste para o modelo de Page $\left(\mathrm{R}^{2}=0,9994\right)$ e para a solução analítica do modelo de difusão de Fick para uma esfera $\left(\mathrm{R}^{2}=0,9573\right)$. $\mathrm{O}$ valor da difusividade mássica foi igual a $8,2 \cdot 10^{11} \mathrm{~m}^{2} \mathrm{~s}^{-1}$.
\end{abstract}

\section{INTRODUÇÃO}

A secagem é um processo utilizado para a remoção de umidade, visando à conservação de produtos alimentícios e/ou modificação de sua estrutura, além de minimizar os pesos para o transporte (ROSSELLÓ et al., 1996). Em engenharia, a secagem é compreendida por ser uma combinação dos processos de transferência de calor e de massa. A água e outros fluídos voláteis, são evaporados da amostra a fim de produzir um sólido com teor de umidade inferior ao inicial. A transferência de massa ocorre por meio da difusão e/ou convecção entre o sólido úmido e o ar de secagem. Compreender e projetar um processo de secagem envolve a medição de parâmetros de processo e cálculo dos balanços de massa e energia, da termodinâmica, das taxas de transferência de massa e calor e das considerações sobre a qualidade do produto como, por exemplo, o encolhimento. (GENSKOW et al., 2008). Neste trabalho foi realizado o estudo da cinética de secagem de partículas esféricas de amido de milho e alginato de sódio produzidas a partir da gelificação iônica em cloreto de cálcio. A 
partir dos ensaios experimentais e modelagem matemática, obteve-se o valor da difusividade efetiva para estas partículas.

\section{MATÉRIAIS E MÉTODOS}

\subsection{Preparo da suspensão de amido-alginato}

O preparo das soluções e suspensões foram planejados utilizando-se as formulações em base-seca. Primeiramente, preparou-se amostras de $100 \mathrm{~g}$ de solução aquosa de alginato de sódio (3,5\% w/w), a partir da homogeneização de 96,5 g de água destilada e 3,5 g de alginato de sódio. Posteriormente, foi adicionado $31,5 \mathrm{~g}$ de amido de milho, previamente seco em estufa. Desta forma, após as etapas de gelificação iônica e secagem em estufa, foi possível produzir partículas secas com composição de $90 \%$ de amido de milho e $10 \%$ de alginato de cálcio.

\subsection{Produção de partículas aglomeradas por gotejamento}

O método "dripping" consiste no gotejamento da suspensão amido-alginato em solução de cloreto de cálcio (1\%). Por meio da troca iônica entre os íons de cálcio e o alginato de sódio, a gotas formam um gel rígido, e ocorre a consolidação da partícula aglomerada. No decorrer do processo de gotejamento, a suspensão foi mantida em agitação constante (220 RPM), em um agitador mecânico de 4 pás. A suspensão foi bombeada através de um tubo plástico, com vazão de $3 \mathrm{~mL} / \mathrm{min}$, até o bico gotejador, constituído de uma agulha para com $0,70 \mathrm{~mm}$ de diâmetro interno. A agulha foi posicionada no interior de um tubo de silicone, permitindo a passagem de ar comprimido paralelamente ao sentido da formação das gotas, o esquema simplificado do processo é mostrado na Figura 1A. A Figura 1B apresenta a fotografia do dispositivo utilizado. Após o gotejamento, as partículas aglomeradas foram recolhidas por uma peneira com abertura de $150 \mu \mathrm{m}$ (mesh 100).

Figura 1 - Esquema do método de gotejamento (a) e equipamentos utilizados (b).

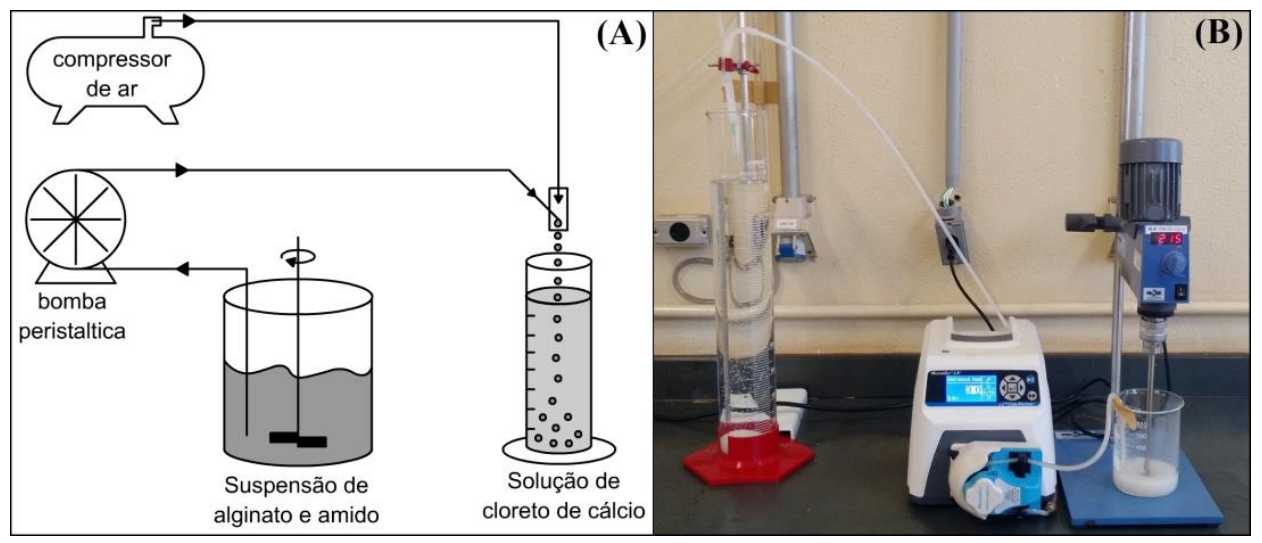

\subsection{Descrição do experimento de secagem}

Cerca de $5 \mathrm{~g}$ de partículas úmidas foram distribuídas em placas de Petri e acondicionadas em estufa convectiva à temperatura de $60{ }^{\circ} \mathrm{C}$ e com velocidade do ar de 0,20 $\mathrm{m} / \mathrm{s}$, como mostra a Fig. 2. A velocidade do ar foi aferida por anemômetro de fio quente 
(Testo 425, Alemanha). No período de 120 min obteve-se o perfil de cinética de secagem, pesando-se as amostras em uma balança analítica a cada $5 \mathrm{~min}$. Foi utilizado um esquema de rodízio entre as placas, anotando-se a massa da amostra e o tempo de duração da secagem. Após a cinética de secagem, as amostras foram mantidas na estufa, por mais 20 horas. Por fim, determinou-se a umidade de equilíbrio em uma balança de halogênio.

Figura 2 - Fotografia do interior da estufa utilizada, com as amostras em placas de Petri durante a secagem a $60{ }^{\circ} \mathrm{C}$ e velocidade do ar a $0,2 \mathrm{~m} / \mathrm{s}$.

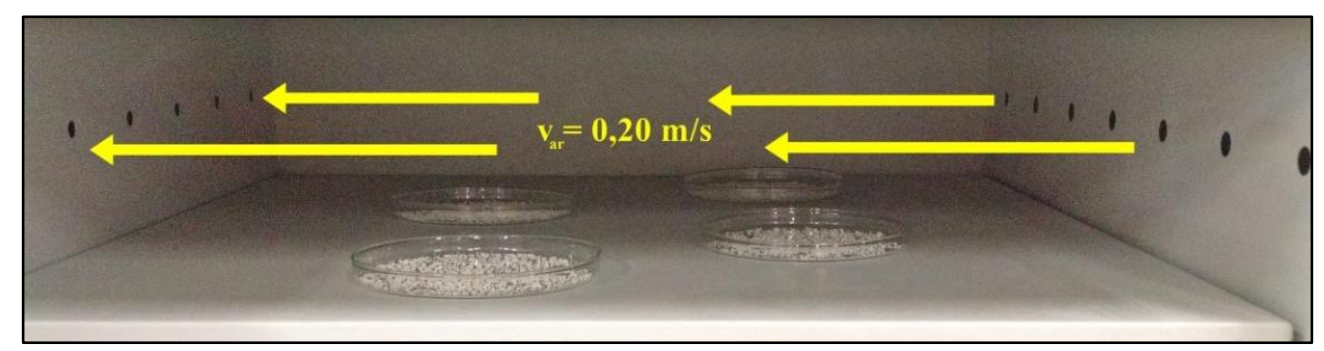

\subsection{Determinação da umidade}

Após a etapa de secagem, foi obtida a umidade de equilíbrio $\left(U_{b . u .}\right)$, em base úmida, em uma balança de halogênio a $120{ }^{\circ} \mathrm{C}$ (Eq. 1). A partir deste valor, foi possível encontrar a umidade em base seca $\left(U_{\text {b.s. }}\right)$ das partículas, pela Eq. 2. A umidade adimensional em base seca foi obtida pela razão Eq. 3 .

$$
\begin{gathered}
U_{b . u .}=\frac{m_{\text {água }}}{m_{\text {amostra }}} \\
U_{b . s .}=\frac{U_{b . u .}}{1-U_{b . u .}} \\
X_{b s}(t)=\frac{U_{b . s .}(t)-U_{e q}}{U_{i-} U_{e q}}
\end{gathered}
$$

\subsection{Ajuste de modelos matemáticos ao perfil de secagem}

O modelo exponencial de Page foi utilizado para ajustar os dados experimentais da secagem (Eq. 5), sendo $k$ e $b$ os parâmetros de regressão do modelo.

$$
\frac{U_{b . s .}(t)-U_{e q}}{U_{i-} U_{e q}}=e^{\left(-k t^{b}\right)}
$$

A Eq. 5 apresenta a solução da segunda lei de Fick para coordenadas esféricas, desprezando-se o encolhimento (Crank, 1975). Utilizando-se o MS Excel, foi possível determinar a difusividade efetiva para a secagem das esferas de géis nas condições de secagem de $60^{\circ} \mathrm{C}$ e $0,2 \mathrm{~m} / \mathrm{s}$.

$$
\frac{U_{b . s .}(t)-U_{e q}}{U_{i-} U_{e q}}=\frac{6}{\pi^{2}} \sum_{n=1}^{\infty} \frac{1}{n^{2}} \exp \left[-\frac{n^{2} \pi^{2} D_{e} t}{R_{e}^{2}}\right]
$$


Os ajustes dos modelos foram obtidos pela ferramenta Solver do software MS Excel. Os parâmetros ajustados, produziram o menor erro entre os valores experimentais e preditos. Por fim, foi calculado o coeficiente de determinação do modelo $\left(\mathrm{R}^{2}\right)$, a fim de se avaliar a qualidade do ajuste dos modelos aos dados experimentais.

\subsection{Distribuição de tamanho das partículas}

Durante a cinética de secagem, as partículas foram fotografadas por um estereomicroscópio (Stereo Discovery V8, Zeiss, Germany), com câmera digital acoplada (Axiocam ICc3, Zeiss), utilizando a escala de ampliação de 1x. As fotografias foram obtidas a cada 20 min a partir do tempo inicial, a fim de se determinar o tamanho médio das esferas. Estas análises de caracterização de tamanho foram realizadas pelo software ImageJ (v1.50i). A partir da fotografia original, utilizou-se diversos filtros de imagem. Primeiramente fez-se a conversão do modo de cor para 8 bit, seguido pela aplicação dos filtros "Gaussian Blur", "Threshold" e "Watershed". Ao final, o software remove as partículas quebradiças e aquelas que estão posicionadas nas bordas da fotografia. Procede-se então as análises de tamanho e forma, obtendo-se os valores de diâmetro médio de partículas, dispersão da distribuição de tamanho (span), circularidade, arredondamento, elongação e compacidade.

\section{RESULTADOS E DISCUSÃO}

\subsection{Cinética de Secagem}

Em 20 horas de secagem, obteve-se a umidade de equilíbrio em base úmida, igual a $5,08 \% \pm 0,19 \%$. A partir da umidade de equilíbrio calculou-se a umidade da amostra nos tempos analisados. Com o auxílio do software gráfico "Origin" foi possível obter a média das curvas de secagem, e obteve-se o perfil apresentado na Figura 3. A umidade (b.u.) inicial foi $63,9 \%$, e decresceu até aproximadamente $50 \mathrm{~min}$ de ensaio, atingindo a umidade de 5,45\%.

Figura 3 - Curva média da cinética de secagem, obtida a partir do software Origin.

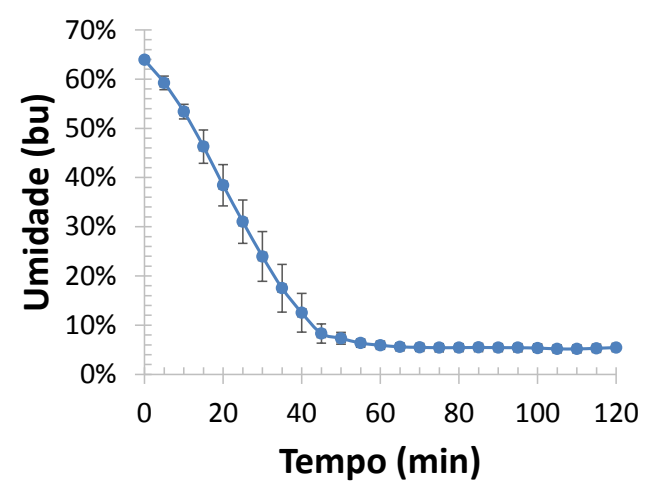

Os pontos do perfil de umidade foram ajustados pelo modelo exponencial de Page (Figura 4a). Considera-se que houve um bom ajuste para a curva de secagem $\left(\mathrm{R}^{2}=0,9994\right)$, pois a variação entre os dados experimentais e do modelo foi pequena. Os parâmetros k e n obtidos a partir da regressão foram iguais a 0,0028 e 1,7782, respectivamente. Para a solução analítica do modelo de difusão de Fick para uma esfera de raio $1,13 \mathrm{~mm}$, Figura $4 \mathrm{~b}$, o valor de $\mathrm{R}^{2}$ foi de 0,9573 . Portanto, também foi considerado um ajuste bom. A partir da regressão, obteve-se o valor da difusividade mássica efetiva, igual a $8,2 \cdot 10^{11} \mathrm{~m}^{2} \mathrm{~s}^{-1}$. 


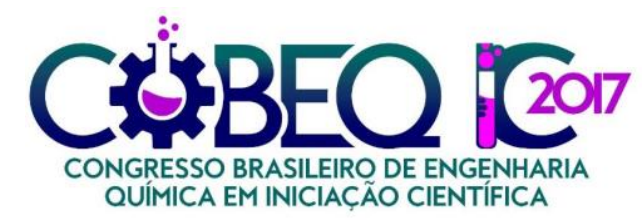

XII Congresso Brasileiro de Engenharia Química
em Iniciação Científica
UFSCar - São Carlos - SP
16 a 19 de Julho de 2017

Figura 4 - Perfil de cinética de secagem e ajustes pelo modelo exponencial de Page (a) e pelo modelo de difusão de Fick para uma esfera (b).

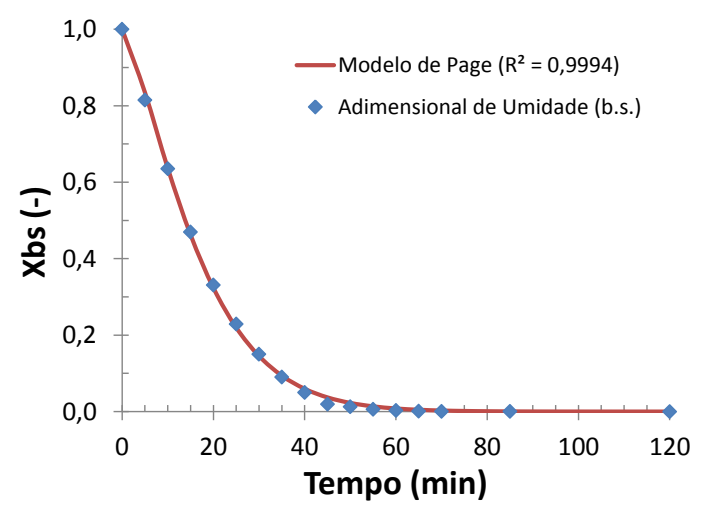

(a)

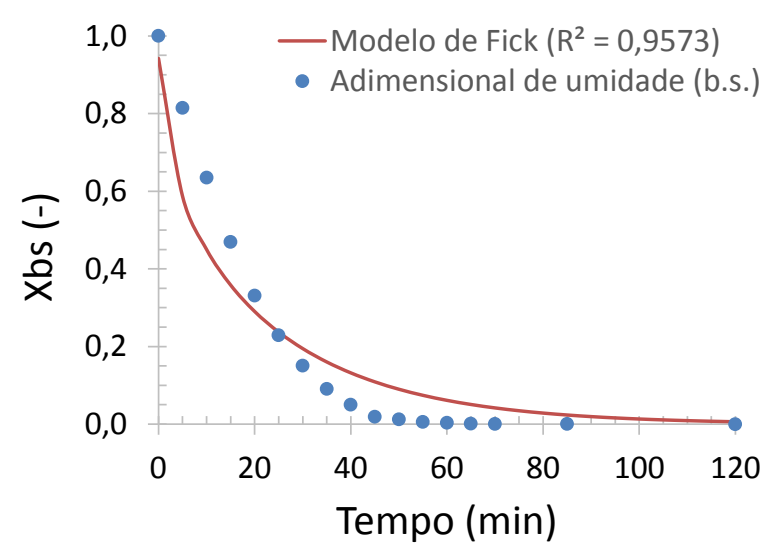

(b)

\subsection{Diâmetro médio e tamanho de partículas}

A Figura 5 mostra as fotos das partículas ao longo do tempo de secagem. Visualmente, é possível perceber a redução de tamanho médio somente nos primeiros minutos, e com auxílio computacional, pôde-se quantificar que houve um encolhimento foi de até $24 \%$.

Figura 5 - Sequência de fotos durante a secagem em estufa a $60^{\circ} \mathrm{C}$, nos tempos $(0,20,40,60$, $80,100,120)$ min e ao final das 20 horas.

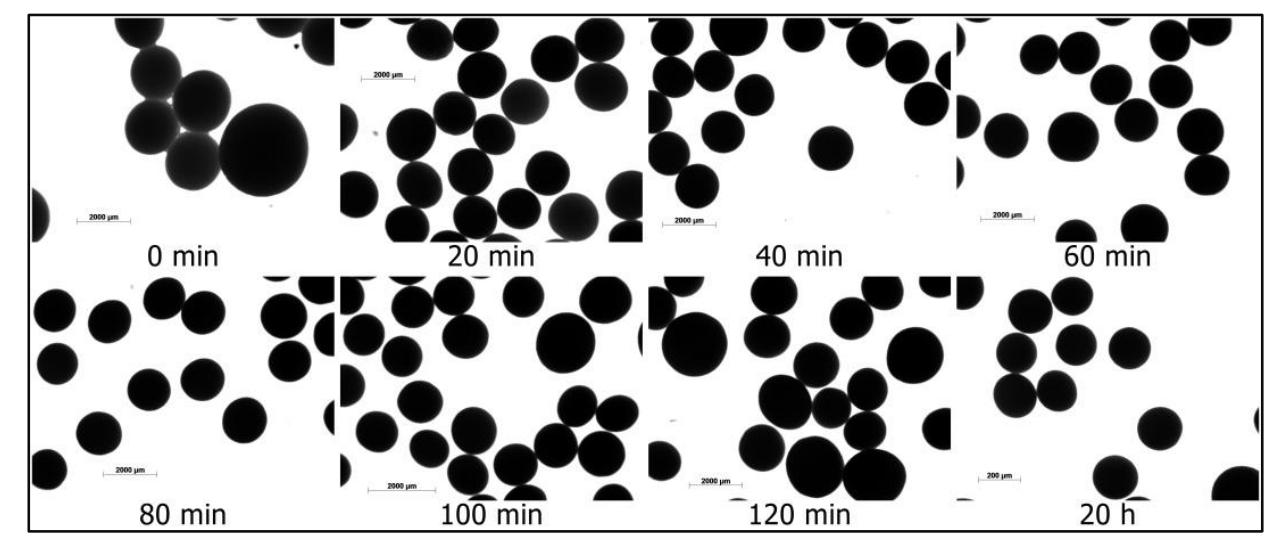

A Tabela 1 apresenta os resultados obtidos de tamanho e forma, a parter das análises das micrografias no software "ImageJ". Pode-se observar que o tamanho médio diminui nos primeiros 40 minutos de secagem. Os valores de diâmetro médio De Brouckere (D4,3) incidam que nos primeiros 20 min há a maior encolhimento, e depois instante o tamanho das partículas flutua entre (1700 e 1800) $\mu \mathrm{m}$. Possivelmente, esta flutuação é decorrente do erro aleatório durante a aquisição das imagens. No entanto, o encolhimento não resultou na alteração da forma das partículas, uma vez que os valores de circularidade $(0,85)$, arredondamento $(0,91)$, elongação $(1,11)$ e compacidade $(0,94)$ foram mantidos constantes durante a secagem. A dispersão da distribuição de tamanho de partículas (span) manteve-se ao redor de 0,30 $\pm 0,1$, o que indica que ao longo do tempo de secagem as partículas com maiores e menores tamanhos apresentaram a mesma taxa de encolhimento. 
Tabela 1 - Caracterização das partículas.

\begin{tabular}{|c|c|c|c|c|c|c|}
\hline $\begin{array}{c}\text { Tempo } \\
(\mathrm{min})\end{array}$ & $\begin{array}{c}\text { D4,3 } \\
(\mu \mathrm{m})\end{array}$ & $\begin{array}{c}\text { Span } \\
(-)\end{array}$ & $\begin{array}{c}\text { Circularidade } \\
(-)\end{array}$ & $\begin{array}{c}\text { Arredondamento } \\
(-)\end{array}$ & $\begin{array}{c}\text { Elongação } \\
(-)\end{array}$ & $\begin{array}{c}\text { Compacidade } \\
(-)\end{array}$ \\
\hline \hline 0 & 2254,3 & 0,23 & 0,85 & 0,87 & 1,11 & 0,94 \\
\hline 20 & 1839,2 & 0,15 & 0,85 & 0,91 & 1,10 & 0,95 \\
\hline 40 & 1709,9 & 0,23 & 0,86 & 0,92 & 1,11 & 0,94 \\
\hline 60 & 1737,8 & 0,22 & 0,86 & 0,92 & 1,10 & 0,95 \\
\hline 80 & 1796,9 & 0,39 & 0,85 & 0,93 & 1,10 & 0,95 \\
\hline 100 & 1709,6 & 0,28 & 0,86 & 0,91 & 1,11 & 0,94 \\
\hline 120 & 1809,2 & 0,43 & 0,86 & 0,92 & 1,11 & 0,94 \\
\hline 1440 & 1729,9 & 0,35 & 0,86 & 0,91 & 1,11 & 0,95 \\
\hline
\end{tabular}

\section{CONCLUSÕES}

A umidade de equilíbrio para as partículas de amido-alginato, nas condições de secagem a $60{ }^{\circ} \mathrm{C}$ e $0,2 \mathrm{~m} / \mathrm{s}$, foi igual a $5,08 \%$. Observou-se um encolhimento de até $24 \%$, em relação ao tamanho inicial, mas os parâmetros de forma mantiveram-se constantes. Os modelos de Page e modelo de Fick apresentaram bons ajustes, com valor de $\mathrm{R}^{2}$ iguais a 0,9994 e 0,9573, respectivamente. A partir do ajuste do modelo de Fick foi possível determinar a difusividade mássica efetiva, igual a $8,2 \cdot 10^{11} \mathrm{~m}^{2} \mathrm{~s}^{-1}$. Embora o modelo de difusão de Fick apresentou bom ajuste aos dados experimentais, estes valores podem ser aprimorados ao avaliar o encolhimento das partículas ao longo da secagem.

\section{NOMENCLATURA}

$D_{e} \quad$ Difusividade efetiva

$k \quad$ Constante empírica do modelo de Page

$R_{e} \quad$ Raio da esfera

$U_{\text {b.u. }} \quad$ Umidade em base úmida da amostra em um tempo definido

$U_{b . s .} \quad$ Umidade em base seca da amostra em um tempo definido

$U_{e q} \quad$ Umidade de equilíbrio em base úmida

$U_{i} \quad$ Umidade em base úmida da amostra no instante inicial

b Constante empírica do modelo de Page

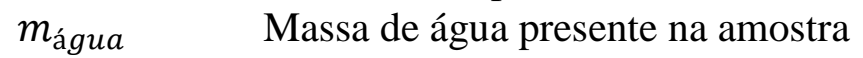

$m_{\text {amostra }} \quad$ Massa total da amostra úmida

n Número de termos do somatório na série

$\mathrm{t} \quad$ Tempo de secagem

Xbs Umidade adimensional em base seca $\left(\mathrm{m}^{2} / \mathrm{s}\right)$

$\left(s^{-b}\right)$

(m)

$(\mathrm{kg} / \mathrm{kg})$

$(\mathrm{kg} / \mathrm{kg})$

$(\mathrm{kg} / \mathrm{kg})$

$(\mathrm{kg} / \mathrm{kg})$

$(-)$

$(\mathrm{kg})$

$(-)$

(s)

$(\mathrm{kg} / \mathrm{kg})$

\section{REFERÊNCIAS}

GENSKOW, L.R. et al. Psychrometry, Evaporative Cooling, and Solids Drying. In: PERRY, R. H. et al. Perry's Chemical Engineers, 8 ed., 2008, Cap. 12, p. 1-113.

ROSSELLÓ, C. et al. Drying models for green peas. Foood Chemistry, Espanha, v. 55, n. 2, p.121-128, mar. 1996. 